\title{
Childhood Bullying, Loneliness and Resiliency-A Critical Review of the Literature
}

\author{
Rivka Edery \\ Private Practice, Brooklyn, New York, USA \\ Email: rebecca.edery@gmail.com
}

Received 2 December 2015; accepted 31 January 2016; published 4 February 2016

Copyright @ 2016 by author and Scientific Research Publishing Inc.

This work is licensed under the Creative Commons Attribution International License (CC BY).

http://creativecommons.org/licenses/by/4.0/

c) (i) Open Access

\begin{abstract}
There are numerous contributing factors that shape an individual's level of resiliency. The experience of childhood bullying (peer victimization), loneliness and resiliency is among them. There is growing research that associates childhood peer victimization to problematic patterns of emotional, behavioral, and academic adjustment among adolescents. The purpose of this literature review is to examine five key studies, which focus on the interplay among childhood bullying, loneliness and resiliency. These five key studies are selected based on the author's assessment of their contribution and significance in data, perspective, and impact on further research.
\end{abstract}

Keywords

Peer Rejection, Resiliency, Loneliness, Bullying

\section{Introduction}

Bullying is generally defined as repeated aggressive and/or unwanted behaviors: verbal, social and physicalmotivated by a real or perceived power imbalance. A power imbalance involves the use of one's strength, knowledge or social acceptance to hurt and/or exploit others. The effects of bullying on children include undesirable mental health, academic and physical issues. Victims of bullying may be plagued with chronic feelings of loneliness, anxiety, depression, difficulty with eating and sleeping, general health complaints, and diminished academic participation and achievement. Without the appropriate intervention, some or all of these issues may continue for many years. Some may react through the use of exceedingly violent actions, as evidenced by the history of school shooting cases in the 1990s. Remarkably, twelve out of the fifteen shooters reported a history of having been bullied [1]. 
Loneliness is an internal sense, based on one's perception of their relation to others, and how others view them, to include feeling disconnected, alienated, unknown, or estranged. A lonely person may not necessarily be alone in actuality, but as one possible result of having been bullied, feels chronically isolated, possibly leading to anxiety, depression, and overall decreased functioning and well-being.

Resilience is the ability to adjust to, and/or recover from calamity. The influence of resiliency on bullying and loneliness is that the lonely victim of bullying, because of his/her resilience, is motivated by hope and not denial. Their resilience allows them to overcome the aversive effects, and perhaps even to move past it. Resiliency can also motivate a victim to utilize their experience for positive change and reformation in this area. According to Dr. Elaine Norman (2000), there are four necessary specific skills in order for one to develop resiliency. They are as follows: 1) Social problem solving skills, 2) Self-efficacy skills, 3) Empathy skills, and 4) Purpose in life [2].

The first study, we will examine, was conducted by researchers Graham and Juvonen [3]. They have improved other studies by analyzing the issues surrounding identification of victim status groups. The main goal of this study was to answer two questions not previously answered in peer victimization literature. First, what aspects of their character do they attribute to why they are victimized? Second, how these attributions are connected to the consequences of victimization such as loneliness. It was hypothesized that victims would attribute more self-blaming and characterological reasons than non-victims would, and that characterological self-blame would be linked to more loneliness in adolescents. A sample of 418 twelve-year-old youth, 206 boys and 212 girls, from an ethnically and economically diverse public middle school, was used in this study.

The results offer critical new insights into the dynamics of peer victimization. Middle school students, who see themselves as victimized, are vulnerable to loneliness and social anxiety. The researchers also found that the characterological self blame was connected to their assumptions that somehow they were a failure. However, the results are too simplistic to conclude that victimized adolescents blame themselves for being a victim, or that self-blame always has negative implications. Once can conclude that certain types of self-blame are particularly harmful, while others may be relatively harmless. While very insightful, this study is limited because the researcher identified more "paranoids" [3] than true victims, suggesting that this is a group in need of further study.

The second study, by researchers Asher and Parkhurst (1992) [4], addresses the behavioral and cognitive-behavioral aspects of victimization. They were particularly interested in examining the behavioral characteristics of bullies and their victims. To do so, they examined the extent to which aggressive and submissive students were not rejected. Their results were compared with responses from rejected students who were similarly aggressive or submissive. Their main focus was on the emotional experiences of rejected children, specifically on the feelings of loneliness.

The researchers put three hypotheses forth. First, loneliness and social anxiety would be particular characteristic of submissive-rejected adolescents. Second, aggressive-rejected students compared with average students would be more concerned about getting even, proving their strength, getting their way, and stirring up excitement. And third, both subgroups of rejected children would have less concern (than average students) for other people's feelings and the effects of their actions on them.

An interesting finding as pointed out by the researchers was that these two subgroups of peer-victimized children viewed their peers as unable to handle being teased. The results of the present study leave an important question unanswered. What are the emotional experiences of the subgroup of submissive/withdrawn peer-victimized children? (There is much less data available on them). The results of this study suggest that both groups of rejected students would benefit from interventions that help them increase their pro-social skills. The researchers made it a point to mention that the most successful interventions with rejected children had focused mostly on teaching them concepts and skills like cooperativeness, friendliness, and supportiveness. A question for further research would be if all peer-marginalized children can or would derive equal benefit from such interventions.

The third study compared the levels of self-esteem in adolescents who were childhood bullies, victims of bullying, and "normals". Tritt and Duncan (1997) [5] investigated the levels of self-esteem found in adolescents who bullied other children during their childhood, bully victims, and those that were neither, i.e. "normals". The main focus was to expand their understanding of the long-term links of childhood bullying such as young adult self-esteem and loneliness.

The sample consisted of 86 male undergraduate students and 120 female students; both groups just exiting 
their adolescence stage. 19 males and 6 females were identified as bullies, 13 females and 8 males were classified as victims, and 101 females and 59 males were identified as "normals". It was predicted that: l) Childhood bully victims had lower levels of self-esteem than bullies and "normals" and that "normals" and bullies would have similar levels of self-esteem, 2) bully victims would be lonelier than bullies or "normals" (this is because bully victims are typically introverted), and 3) bullies had alienated others because of their behavior, and often did not have the proper social skills to initiate and maintain satisfying relationships. Consequentially, the researchers predicted that young adults who were child-bullies would be lonelier than "normals".

The results show higher levels of loneliness experienced by bullies and their victims, in comparison to those who were not in either position. Further research may try to find out what other variables are related to loneliness. Some examples include hostility in bullies and shyness in their victims. Research for intervention can incorporate a more targeted and accurate focus for those in either category.

The fourth study focused on two main goals guided by researchers Kochenderfer-Ladd \& Skinner (2002) [6]. The first goal was to consider why peer marginalization hurts some children more than others. The second was to resolve the contradictory evidence found in the majority of the peer victimization research: peer victimization is a form of abuse preventing children from healthy development. The focus of the investigation was on the differences among coping strategies utilized, and the effects that showed up later on in their lives. The strategies used were dependent on their experiences of being bullied and the social gender expectations (different for boys and girls). It is hypothesized that the level of risk of being victimized by one's peers partly depended on how the children coped with it.

The sample consisted of 356 ethnically diverse 9 - 10 year old children, 177 girls and 179 boys. Findings revealed that coping strategies and loneliness helped non-victims, but increased the difficulties of victimized children. The effectiveness of the coping strategies used depended on the child's gender. Victimized girls who sought social support were buffered from social problems, but with victimized boys, seeking social support was less acceptable. As with other researcher's findings on this topic, the risk level for victimization was equal for both sexes.

This data can play an important role in developing school-based programs. One example of an effective school-based program would include teaching boys skills on how to independently handle conflicts effectively, without violence or hostility [6]. In contrast, if girls ignored their peer problems they experienced more loneliness and greater social problems than girls who did not. The authors suggest that by girls pretending they did not have peer problems, they will not share their experiences with others, denying them validation of their experiences. Isolation, which leads to loneliness, is a form of distancing and a coping strategy. When employed by both girls and boys, problems are intensified for both genders.

And finally, researchers Chadwick, Hay and Payne [7], propose a developmental model that describes normal peer relations and draws attention to what underlies problems with peers. Based on their research they state that peer relations begin in the first years of life. Social skills that facilitate peer relationships are strengthened in the preschool years, at which time peer groups are set up with respect to gender, friendships, and dominance relations. This is the point in time that some children begin to get rejected by their peers. Later on some of them will develop problems with peer relationships, such as bullying, victimization, and loneliness.

The main focus of this study is to identify the cognitive and emotional processes that assist in successful peer relationships, and to evaluate the extent to which peer relations play a causal role in the development of later problems, such as excessive loneliness in adolescence. It is hypothesized that there is no one simple pathway from problematic peer relations to later problems, but rather, there is a reciprocal relationship between children's problems with peers and their psychological difficulties in adolescence. The main point is that the relationship between peer relations and children's risk for disorder is best understood by taking the long view, starting with examining the early development of the ability to relate to peers. Their model outline contains a pathway showing the development from early peer relationships to peer relations in adolescence. Competency in dealing with peers depends partly on social skills and the ability to regulate oneself. Although the exact causes of being accepted or rejected by peers are not known, early peer relations will determine the risk for victimization, influence by deviant peers, and development of psychological difficulties.

This study is limited because it does not provide specific data on a causal pathway between early peer relationships and later on peer victimization. However, it does contribute to the efforts of researchers to understand the internal experiences of adolescents who were bullied as children, and who internalize problems via isolation and loneliness, and as a result, may suffer academically and socially. The researchers claim that social difficul- 
ties later on will impact the choice of intimate partners, and may encourage early sexual relations and parenthood. Noteworthy, is that the authors make a distinction between loneliness and solitude. If adolescents spend time in solitude, it can have a positive effect on their emotional state and they will be better adjusted. The strength of this research is that it provides a critical resource for those studying the significance of childhood peer relations, or are interested in childhood disorders.

\section{Conclusions}

Childhood peer relationships render the topic of childhood bullying a very worthy discussion. The existing literature of childhood bullying provides abundant insight regarding the effects of having been bullied in childhood. Further research is indicated in exploring the relationship between the bully and their victims. Both parties suffer the consequences of this unfortunate aspect of childhood, and without the appropriate intervention, the consequences linger well into adulthood. Bullies have underlying significant issues, including the possibility of having been, or currently, experiencing abuse in the home. Perhaps their need to bully others is driven by their perception of their victim as being weak and vulnerable. If this proves to be true, examining their motivation perhaps needs to annihilate those characteristics they loathe in themselves; they seek and bully those that give that impression. Sadly, the victims are often carriers of low-self esteem, are shy in character, and experience loneliness that deepens their suffering. They may feel compelled to hide their story and their suffering, driven by a sense of unworthiness. Their resiliency may further give them the impression that they do not need any intervention, comfort for their wounds, or guidance in developing necessary social skills.

Understanding and exploring the deeper issues involved in bullying, and therefore in shaping and supporting appropriate interventions, are key in aiding both the bully and their victims. Further, targeted research investigating relationships between aggressive, hostile and abusive symptomatology, in the child-bully, and specific characteristics of their chosen victims, is recommended if one is interested in probing such dynamics and enhancing existing interventions.

The ultimate goal would be to completely eliminate childhood bullying, a goal that is not possible in its entirety, although it's a dream of many. However, a more feasible goal would be to include a method whereby both the victim and the bully can have more access to those parts of themselves that are involved in this very painful dynamic. It is well supported that education influences and shapes human behavior. For children this is a critical aspect of the intervention that cannot be replaced. Education includes understanding one's personal vulnerabilities, and how to embrace or reject them, and the effects the most critical of dynamics have between themselves and others.

\section{References}

[1] Effects of Bullying. www.stopbullying.gov

[2] Norman, E. (2000) Resiliency Enhancement: Putting the Strengths Perspective into Social Work Practice. Columbia University Press, New York.

[3] Graham, S. and Juvonen, J. (1998) Self-Blame and Peer Victimization in Middle School: An Attributional Analysis. Developmental Psychology, 34, 587-599. http://dx.doi.org/10.1037/0012-1649.34.3.587

[4] Asher, S. and Parkhurst, J. (1992) Peer Rejection in Middle School: Subgroup Differences in Behavior, Loneliness, and Interpersonal Concerns. Developmental Psychology, 28, 231-241. http://dx.doi.org/10.1037/0012-1649.28.2.231

[5] Duncan, R. and Tritt, C. (1997) The Relationship between Childhood Bullying and Young Adult Self-Esteem and Loneliness. Journal of Humanistic Education \& Development, 36, 35-42. http://dx.doi.org/10.1002/j.2164-4683.1997.tb00426.x

[6] Kochenderfer-Ladd. B. and Skinner, K. (2002) Children’s Coping Strategies: Moderators of the Effects of Peer Victimization. Developmental Psychology, 38, 267-278. http://dx.doi.org/10.1037/0012-1649.38.2.267

[7] Chadwick, A., Hay, D. and Payne, A. (2004) Peer Relations in Childhood. Journal of Child Psychology and Psychiatry, and Allied Disciplines, 45, 84-108. http://dx.doi.org/10.1046/j.0021-9630.2003.00308.x 